\title{
The Length of the Male Urethra
}

\author{
Tobias. S. Kohler, Mitchell Yadven, Ankur Manvar, Nathan Liu, Manoj Monga
}

Division of Urology (TSK), Southern Illinois University, Springfield, IL, Department of Urologic Surgery (MY, NL, MM), University of Minnesota, Minneapolis, MN, Department of Urologic Surgery (AM), Northwestern University, Feinberg School of Medicine, Chicago, Illinois, USA

\begin{abstract}
Purpose: Catheter-based medical devices are an important component of the urologic armamentarium. To our knowledge, there is no population-based data regarding normal male urethral length. We evaluated the length of the urethra in men with normal genitourinary anatomy undergoing either Foley catheter removal or standard cystoscopy.

Materials and Methods: Male urethral length was obtained in 109 men. After study permission was obtained, the subject's penis was placed on a gentle stretch and the catheter was marked at the tip of the penis. The catheter was then removed and the distance from the mark to the beginning of the re-inflated balloon was measured. Alternatively, urethral length was measured at the time of cystoscopy, on removal of the cystoscope. Data on age, weight, and height was obtained in patients when possible.

Results: The mean urethral length was $22.3 \mathrm{~cm}$ with a standard deviation of $2.4 \mathrm{~cm}$. Urethral length varied between 15 $\mathrm{cm}$ and $29 \mathrm{~cm}$. No statistically significant correlation was found between urethral length and height, weight, body mass index (BMI), or age.

Conclusions: Literature documenting the length of the normal male adult urethra is scarce. Our data adds to basic anatomic information of the male urethra and may be used to optimize genitourinary device design.
\end{abstract}

Key words: genitourinary; catheter; urethra

Int Braz J Urol. 2008; 34: 451-6

\section{INTRODUCTION}

The Egyptians developed the first use of catheters by using an instrument made of reed that was inserted like a plug. The term "katheter" originates from "kathiemai," meaning 'to sound' with a probe. The Greeks further developed this katheter by using a hollow metal tube inserted into the male urethra to empty the bladder.

Modern day catheter use is ubiquitous and catheter-based medical devices are an important component of the urologic armamentarium. Since its development in 1935, use of Frederick Foley's urethral catheter has remained pervasive with little modification to its design. Current urethral catheters typically measure 40-45 $\mathrm{cm}$ in length. With recent developments of new catheter-based treatments such as microwave therapy of the prostate or cryotherapy, specialized catheters have been developed. One would expect further novel catheter use in the future, and perhaps a departure from the standard Foley design to optimize bladder drainage, minimize cost and improve patient comfort. In addition, the length of flexible and rigid endoscopes for transurethral applications would benefit from standardization based on the expected length of the male urethra. As such, defining the mean length of the male urethra is critical. 
Despite an extensive online literature search and review of anatomic atlases, only one reference to the anatomic length of the male urethra was found. Gray's Anatomy describes a male urethral length of 17.5 to $20 \mathrm{~cm}$ (1). However, an exhaustive review of the aforementioned citation's reference list suggests that supportive evidence is lacking. One prior study utilizing retrograde urethrograms noted that the membranous urethral length ranged from 1 to $1.5 \mathrm{~cm}$ (2). A second study reported that the average prostatic urethral length was $2.4 \mathrm{~cm}$ (3). Lastly, a more detailed anatomical study reports the urethral length for an infant male to be $5.6 \mathrm{~cm} \mathrm{(4).}$

\section{MATERIALS AND METHODS}

The study was initiated after IRB consent from all participating institutions was obtained. Patients were recruited from a large Midwest Veteran's Administration Hospital and from a private urologic practice in Florida. Subjects with a history of prostatectomy or urethral surgery were ineligible for the study. To measure urethral length, two methods were employed. The majority of subject data was obtained upon removal of an indwelling Foley catheter. Prior to catheter removal, the subject's penis was placed on a gentle stretch, the balloon of the catheter was gently "cinched" to the bladder neck, and the catheter was marked at the tip of the penis with tape. The catheter was then removed and the distance from the mark to the beginning of the re-inflated balloon was measured in centimeters $(n=79)$. Alternatively, urethral length was established at the time of flexible cystoscopy upon removal of the cystoscope.
The scope was held fixed at the bladder neck with the penis on stretch and the cystoscope was similarly marked with tape at the end of the penis. The cystoscope was then removed and the distance from the mark to the end of the cystoscope was measured in centimeters $(n=30)$. Stretched penile length has previously been established as surrogate marker for erect penile length (5). No measurements of separate prostatic, membranous, bulbar or pendulous urethral segments were obtained. After measurement was completed, subject data on age, weight, and height was obtained in most patients. BMI was calculated as $\mathrm{kg} /$ meter $^{2}$. All statistics were performed using SPSS software.

\section{RESULTS}

Data was collected on 109 men. The mean urethral length was $22.3 \mathrm{~cm}$ with a standard deviation of $2.4 \mathrm{~cm}$. Mean values for age, weight, height, and body mass index (BMI) were 70.7 years, $92 \mathrm{~kg}$, 1.8 meters, and $28.6 \mathrm{~kg} / \mathrm{m}^{2}$ (Table-1). Urethral length varied between $15 \mathrm{~cm}$ and $29 \mathrm{~cm}$. The distribution of urethral length is shown in Figure-1. No statistically significant correlation was found between urethral length and weight, height, BMI, or age utilizing Pearson's correlation 2-tailed test (Table-2).

\section{COMMENTS}

Literature documenting the length of the normal male adult urethra is scarce. This study determined the average urethral length to be about $22 \mathrm{~cm}$

Table 1 -Descriptive statistics $(n=109)$.

\begin{tabular}{lccrc}
\hline & Minimum & Maximum & Mean & SD \\
\hline Age & 42.0 & 89.0 & 70.7 & 12.2 \\
Weight $(\mathrm{kg})$ & 61.0 & 141.0 & 92.0 & 17.8 \\
Height $(\mathrm{m})$ & 1.7 & 2.0 & 1.8 & 0.1 \\
BMI $(\mathrm{kg} / \mathrm{m}(\mathrm{m}))$ & 20.0 & 44.5 & 28.6 & 5.4 \\
Urethra $(\mathrm{cm})$ & 15.0 & 29.0 & 22.3 & 2.4 \\
\hline
\end{tabular}

$S D=$ standard deviation $; B M I=$ body mass index. 


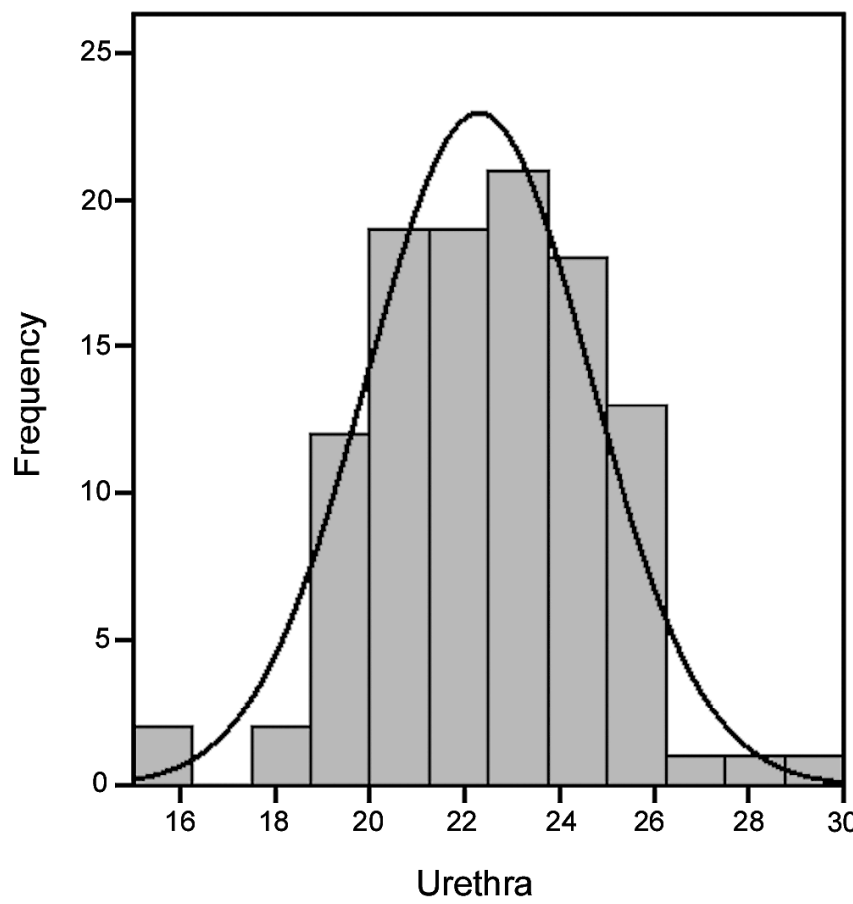

Mean: 22.3

Standard Deviation: $2.4 \mathrm{~cm}$

$\mathrm{N}=109$

Figure 1 - Urethral length (cm) distribution.

with a standard deviation of $2.4 \mathrm{~cm}$. Our data adds to basic anatomic information of the male urethra and may be used to optimize genitourinary device design.

Table 2 - Correlations.

\begin{tabular}{lc}
\hline & Urethra \\
\hline Age & 0.19 \\
$\quad$ Pearson correlation & $\mathrm{p}=0.26$ \\
Significance (2-tailed) & 0.09 \\
Weight & $\mathrm{p}=0.58$ \\
$\quad \begin{array}{l}\text { Pearson correlation } \\
\text { Significance (2-tailed) }\end{array}$ & 0.08 \\
Height & $\mathrm{p}=0.59$ \\
$\quad \begin{array}{l}\text { Pearson correlation } \\
\text { Significance (2-tailed) }\end{array}$ & 0.06 \\
BMI & $\mathrm{p}=0.7$ \\
$\quad$ Pearson correlation & \\
Significance (2-tailed) &
\end{tabular}

$B M I=$ body mass index.
Current designs have an average length around 40$45 \mathrm{~cm}$, regardless of the lumen size (Table-3). This design is almost double the length of the average male urethral length. Our mean determination or urethral length incorporates differences in penile length and prostatic urethral length, two factors that have a wide variability. Prostatic lengths have been shown to range from $(2.5-4.5 \mathrm{~cm})$ influenced by both baseline anatomy, and the effect of benign prostatic hyperplasia (6). Our study excluded those with prostatic surgery, but allows for the random variation of prostate size attributable to benign prostatic hyperplasia of our age population. Any variation on prostate length would be accounted for by the standard deviation of our urethral length determination. Similarly, penile lengths are variable in the population. We used stretched penile length in our measurements as it is the only validated surrogate marker for erect length (5). Previous studies have compared both stretched and flaccid penile length to height and found no statistically significant correlation (7). Finding of a positive correlation between urethral length and 
Table 3 - Catheter lengths for $16 F$ adult catheters.

\begin{tabular}{lcc}
\hline Catheter Manufacturer & Length (inches) & Length $(\mathrm{cm})$ \\
\hline Bard & 16 & 41 \\
Cook & 13.4 & 34 \\
Boston Scientific & 19.7 & 50 \\
Rochester Medical & 15.9 & 40 \\
\hline
\end{tabular}

Average adult catheter length $=16.2$ in or $41 \mathrm{~cm}$.

height has intrinsic appeal, as one could then predict which catheter length would be appropriate (similar to selecting ureteral stents based on height). However, our findings parallel the penile length data, where no statistically significant correlation between height or BMI and urethral length were found $(\mathrm{p}=0.7)$.

By measuring the total male urethral length of our subjects, we are able to obtain a mean length and calculate a standard deviation. Thus, ideal future catheter design seeking to minimize excess catheter material requirements should aim for an intra-urethral length of about $22 \mathrm{~cm}$ with variations in length 1-2 standard deviations above and below this length. Based on our results, catheter manufacturers could design catheters that would accommodate the majority of male patient's urethras: 17 to $27 \mathrm{~cm}$. Other authors have determined maximum total penile and urethral extensibility, further justifying the rationale for shorter catheter design (8).

\section{CONCLUSION}

Literature documenting the length of the normal male adult urethra is surprisingly scarce. Our study found the average length of the male urethra was $22.3 \mathrm{~cm}$ and there was no statistically significant correlation between urethral length and height. Our data adds to basic anatomic information of the male urethra and may be used to optimize genitourinary device design.

\section{CONFLICT OF INTEREST}

None declared.

\section{REFERENCES}

1. Gray H: Anatomy of the Human Body. Philadelphia, Lea \& Fiberger. 1985, 13th ed.

2. McCallum RW: The adult male urethra: normal anatomy, pathology, and method of urethrography. Radiol Clin North Am. 1979; 17: 227-44.

3. Rolnick HC, Arnheim FK: An anatomic study of the external urethral sphincter in relation to prostatic surgery. J Urol. 1949; 61: 591-603.

4. Parker AE: The lymph vessels from the posterior urethra, their regional lymph nodes and relationships to the main posterior abdominal lymph channels. J Urol. 1936; 36:538-57.

5. Wessells H, Lue TF, McAninch JW: Penile length in the flaccid and erect states: guidelines for penile augmentation. J Urol. 1996; 156: 995-7.

6. Elshaikh MA, Angermeier K, Ulchaker JC, Klein EA, Chidel MA, Mahoney S, et al.: Effect of anatomic, procedural, and dosimetric variables on urinary retention after permanent iodine-125 prostate brachytherapy. Urology. 2003; 61: 152-5.

7. Awwad Z, Abu-Hijleh M, Basri S, Shegam N, Murshidi M, Ajlouni K: Penile measurements in normal adult Jordanians and in patients with erectile dysfunction. Int J Impot Res. 2005; 17: 191-5.

8. Da Silva EA, Sampaio FJ: Urethral extensibility applied to reconstructive surgery. J Urol. 2002; 167 : 2042-5.

Accepted after revison:

June 10, 2008

\section{Correspondence address:}

Dr. Tobias S. Köhler

Southern Illinois University School of Medicine

Division of Urology

PO Box 19638

Springfield, IL, 62794, USA

E-mail: gambitguy@hotmail.com 


\section{EDITORIAL COMMENT}

This study assessed urethral length in 109 men aged 42-89 years at the time of Foley catheter removal or whilst undergoing flexible cystoscopy. The authors found a mean urethral length of $22.3 \mathrm{~cm}$ (range 15-29, SD 2.4) and suggest the finding might lead to revised catheter designs with intra-urethral lengths ranging from 17 to $27 \mathrm{~cm}$. It is proposed that customized catheter lengths would save on excess catheter materials, reduce costs and improve patient comfort. Although the results are interesting, altering catheter design in relation to the data may not necessarily achieve these aims. Optimal patient comfort, for example, requires sufficient extra-urethral catheter length for ease of appliance attachment and for tension-free catheter immobilization with adhesive tape. In addition, the production of catheters with such a restrictive length would undoubtedly cause problems in the occasional patient with well-above average penile length.

\author{
Dr. K. A. Hutton \\ Department of Pediatric Surgery \\ University Hospital of Wales \\ Heath Park, Cardiff, South Glamorgan \\ Wales, United Kingdom \\ E-mail:kim.hutton@cardiffandvale.wales.nhs.uk
}

\section{EDITORIAL COMMENT}

Albert Einstein was quoted to say, "Everything should be as simple as it is, but not simpler", and the study design and methods of this paper could certainly be considered simple. The authors of this study attempt to measure the length of the normal male urethra by either direct cystoscopic measurements $(\mathrm{n}=30)$ or by marking indwelling urethral catheters prior to removal $(n=79)$. They found that the average stretched male urethral length is $22 \mathrm{~cm} \pm 5 \mathrm{~cm}$. Per their literature review, there has been no previous at- tempt at a population-based urethral length evaluation. When considering all the times that we as urologists traverse this area blindly (urethral catheter placement, sounds, transurethral microwave thermotherapy, the new prostate SpannerT), I am astounded to find that this is the first study to address this issue. Although no statistically significant predictor of urethral length was identified, I predict that the urethral length conclusion of this study will ("simply" put) be quoted in anatomy textbooks for years to come.

Dr. Benjamin K. Canales Assistant Professor of Urology University of Florida Gainesville, Florida, USA E-mail: benjycanales@yahoo.com 


\section{EDITORIAL COMMENT}

The authors measured the urethral length in 109 men, 42 to 89 years old, and found that it varied between 15 and $29 \mathrm{~cm}$ (mean $22.3 \pm 2.4$ ). They noted that the currently used catheters have an average length of 40 to $45 \mathrm{~cm}$, which is almost double the average male urethral length. Thus, they suggest that future catheter design should aim for an intra-urethral length of $22 \pm 2 \mathrm{~cm}$ to minimize cost. This may be applied also for the design of catheter-based genitourinary devices.
The authors are to be congratulated for this interesting and unprecedented idea. However, the current study is limited by the relatively small number of patients and by missing the group of patients younger than 42 years. The authors are to be encouraged to corroborate on this issue using a larger number of patients and including all age groups. Thus, they might be able to stratify the length of male urethra - and accordingly the appropriate catheter - into 3 categories: short, medium, and long.

Dr. M. M. Koraitim

Department of Urology University of Alexandria College of Medicine Alexandria, Egypt E-mail:koraitim_mm@yahoo.com 